\title{
Truth Monism Without Teleology
}

\author{
Kurt Sylvan \\ Rutgers University
}

Some say the swamping problem confronts all who believe that true belief is the sole fundamental epistemic value (“T-Monism", to use Duncan Pritchard's term). This, I say, is mistaken. The problem only confronts T-Monists if they grant two teleological claims: (i) that all derived epistemic value is instrumental, and (ii) that it is the state of believing truly rather than the standard of truth in belief that is fundamentally epistemically valuable. T-Monists should reject (i) and (ii), and appeal to a non-teleological form of value derivation I call Fitting Response Derivation that obviates swamping. Since, alas, simple reliabilists can't apply this model to knowledge, the problem remains for them, and is local.

Keywords epistemic value; epistemic teleology; value of knowledge; value of epistemic rationality; swamping problem

DOI:10.1002/tht.26

\section{A generalized swamping problem?}

It is seductive to think that truth is fundamental to epistemic normativity. One way to make this precise is to say that truth (in belief) is the sole fundamental epistemic value; following Duncan Pritchard, call this claim "T-Monism". Some, however, say that this claim is doomed, thanks to the generalizability of a problem for simple reliabilism called the swamping problem.

This verdict rests, I'll argue, on false assumptions about how all epistemic value could derive from that of true belief, and about what it is for true belief to be epistemically valuable. We should recognize more pathways for value derivation than teleological, means-end pathways, and see the standard of truth in belief as evaluatively basic, not the state of believing truly. If we do, T-Monism avoids the problem.

\section{The original problem}

To bring this out, let's consider the original swamping problem, and why some say it generalizes to all views on which true belief is the sole fundamental epistemic value.

The problem started as one for simple reliabilist accounts of knowledge. ${ }^{1}$ We want to say that:

(1) Any epistemic value had by reliability is merely instrumental relative to the more fundamental epistemic good of true belief. 
Yet, plausibly:

(2) The fact that a belief was reliably produced cannot add epistemic value to it if it is already true.

One reason to believe (2) emerges via an analogy. ${ }^{2}$ We value effective coffee makers instrumentally, because they reliably produce good coffee. Yet if we already know that some coffee is good, the fact that it was produced by such a maker is no extra plus in it. Hence, the coffee's goodness swamps that of its reliable ancestry.

The same thinking applies to the comparison between reliably formed true belief and true belief. But if so, then:

(3) If knowledge is reliably formed true belief, it cannot be epistemically better than true belief.

Yet knowledge is epistemically better than true belief.

This is the original swamping problem. It is clearly not a problem just for simple reliabilist theories. It confronts any view on which knowledge stands to true belief as good coffee produced by an effective coffee maker stands to good coffee. So it undermines any view on which the epistemic value of knowledge is only instrumental relative to true belief.

\section{Pritchard's generalization}

More boldly, Pritchard $(2010,2011)$ claims that it confronts all who uphold:

T-Monism. "True belief is the sole fundamental epistemic good." (2010: 14)

If a face-value reading of T-Monism were central to the problem, that would be important. For Pritchard is right that " $[\mathrm{m}]$ any epistemologists would be attracted to ... T-Monism, at least pre-theoretically", and that some even assume "it is a mere truism that the ultimate epistemic good just is the good of true belief, and hence that all other epistemic goods must be understood relative to this ultimate epistemic good" (2010: 14).

Curiously and crucially, however, Pritchard makes a stipulation about the meaning of 'fundamental' in unpacking his argument:

"Fundamental". "A good is fundamental ... if its value is not instrumental relative to further goods of the same type.” (2011: 245; cf. 2010: 12)

This, in turn, implies that a good is non-fundamental only if it is instrumental.

Given this, Pritchard is partly verbally right. For then T-Monism turns into:

Teleological T-Monism. "The epistemic value conferred on a belief by that belief having an epistemic property is instrumental epistemic value relative to the further epistemic good of true belief." (2010: 15; 2011:248)

And this conflicts with the conjunction of:

Swamping Premise. "If the value of X is only instrumental relative to a further good and that good is already present, then it can confer no additional value." (2010: 15; 2011:248) 
and

Minimal Knowledge Intuition. "Knowledge that $p$ is sometimes more epistemically valuable than mere true belief that $p$. ." (2010: 15; 2011: 249)

Pritchard takes this to show that the swamping problem has the general import suggested by the earlier quotes. Indeed, he thinks it can only be escaped in three surprising ways:

(A) By claiming that the list of fundamental epistemic goods includes something other or more than true belief $(2011, \$ 4)$.

(B) By denying that knowledge is epistemically better than true belief $(2011, \S 3)$.

(C) By holding that knowledge has extra final value simpliciter $(2011, \S 5)$.

This, however, is an incomplete picture of our options.

For the stipulation embodied in "Fundamental" conceals an option that is compatible with a face-value reading of T-Monism. No T-Monist should understand 'fundamental' via Pritchard's stipulation. If some do, that is their mistake. So, I'll argue:

- The thought that true belief is fundamental to epistemic value shouldn't be framed in the claim that all other epistemic values are only instrumental to it,

and

- If it isn't, we needn't choose among only (A-C).

It is the concealment of a better option that concerns me, not any claims Pritchard makes using the contrived sense of 'fundamental'. This is not to change the subject. What should interest us is the status of the seductive thought that truth is fundamental to epistemic value in an intuitive sense of 'fundamental', not of the unseductive thought that truth is fundamental to epistemic value in some stipulative sense.

\section{The ignored option: non-teleological value derivation}

Let's start by using 'the fundamental value' (of some type) in this neutral, natural way: the value in virtue of which all other things with value (of the same type) derive value. For X to derive value in virtue of the fact that $\mathrm{Y}$ has value, $\mathrm{X}$ must stand in some special relation to $\mathrm{Y}$. Call such relations value-derivation relations.

If we read "Fundamental" with 'fundamental' used this way, it implies:

Teleology about Non-Fundamental Value $\left(\mathrm{T}_{\mathrm{NFV}}\right)$. Value-derivation relations are always instrumental: $\mathrm{X}$ has value in virtue of $\mathrm{Y}^{\prime}$ s having value only if an instrumental relation links $\mathrm{X}$ and $\mathrm{Y}$.

This is because, if read substantively rather than stipuatively, "Fundamental" implies that something has non-fundamental value only if its value is instrumental relative to further items of the same type, as $\mathrm{T}_{\mathrm{NFV}}$ suggests.

But $\mathrm{T}_{\mathrm{NFV}}$ is dubious, as is the related idea that all fundamental values are goals to which other values are conducive. That idea is rejected by ethicists like Anderson 
(1995), Scanlon (1998), and Parfit (2011), who doubt that being valuable is being "to be promoted". Unsurprisingly, then, I propose to use their idea that there are non-teleological value-fitting responses to explain how other epistemic value could non-teleologically derive from that of the standard of truth in belief.

To bring this out, I'll start with a simpler reason to reject $\mathrm{T}_{\mathrm{NFV}}$ suggested by the intelligibility of this non-instrumental form of value derivation:

Fitting Response Derivation. If $\mathrm{X}$ has value (of some sort) and $\mathrm{R}$ is a fitting response to it, then having $\mathrm{R}$ in response to $\mathrm{X}$ has derivative value (of the same sort). ${ }^{3}$

Fitting Response Derivation explains why admiring the admirable, desiring the desirable, respecting the respectable, etc., are good without bloating the stock of basic values.

That would be hard if instrumental derivation were the only kind. For having the response that is fitting to a basic value doesn't generally reliably lead to further instantiations of it or other basic values. If I admire some basically good X, this may give no one pleasure, nor make other basically good things exist. Still, it's good that I admire X. And it is implausible that admiring such good Xs is a fundamental value in the way beauty and sensory pleasure are. ${ }^{4}$ It seems good because it's a fitting response to something antecedently good. It gets value via this fitting relation.

The fittingness relation is, accordingly, a value-derivation relation beyond the instrumental relation. If so, we should reject $\mathrm{T}_{\mathrm{NFV}}$.

If $\mathrm{T}_{\mathrm{NFV}}$ is rejected for this reason, new options arise for T-Monists. For Fitting Response Derivation contravenes the following thesis:

Generalized Swamping Premise. If the value of a property possessed by an item is only non-fundamental relative to a further good and that good is already present, it can confer no additional value.

It is better if a situation has the property of being one in which a fitting response to X's value exists than it would be if it only had the property of being one in which X exists. Since the former property has only non-fundamental value relative to the latter, given Fitting Response Derivation, the Generalized Swamping Premise fails.

This creates an avenue of response for T-Monists, to be expanded in the next section:

1. They can unpack the claim that true belief is epistemically valuable as the claim that the standard of truth in belief expressed in the injunction "Believe P only if $\mathrm{P}$ is true" is one we ought epistemically to recognize in certain ways. The state of believing truly is epistemically good because it constitutes conformity with this standard.

2. Besides calling for mere conformity, this standard calls for certain non-teleological responses, like respect. ${ }^{5}$

3. Conforming with the standard in a way that manifests such responses is epistemically better than merely conforming, since:

a. Epistemically fitting responses to epistemic value are derivatively epistemically valuable (given Fitting Response Derivation). 
and

b. The pattern of value derivation in (a) undermines the Generalized Swamping Premise. Just as a morally good act is morally better if done intentionally than if done unintentionally, so meeting the standard of truth with respect is epistemically better than merely meeting it.

4. Knowing requires truly believing in a truth-respecting way.

5. So, knowing is epistemically better than truly believing.

6. But since the epistemic value of respect for the standard of truth in belief derives (non-teleologically) from that of this standard, (5) is consistent with T-Monism.

Elaboration will come in the following section. For now, the form of the response is what matters: it shows that T-Monism as such generates no swamping problem.

Notably, this is not a version of any response Pritchard considers. It is not response (C). My view does not entail that knowledge has final value simpliciter. Respect is a properly epistemically fitting response to the properly epistemic value of the standard of truth in belief. It may not matter simpliciter. It is also not a version of pluralism-i.e., of response (A). It is designed to help T-Monism! But it also saves the Minimal Knowledge Intuition (and more). So it is not response (B).

\section{Truth Monism without teleology}

I turn to some elaboration. The suggested alternative is:

Non-Teleological T-Monism. All that is epistemically valuable derives its epistemic value from that of the standard of truth in belief. But the value derivation need not always flow along teleological lines.

How does non-teleological epistemic value derivation work?

The best account, again, has two sources. One is the idea that there are more fitting responses to value than teleological ones like producing. Clearly there must be on this view. What it says is basically valuable is the standard of truth in belief. But a standard can't be produced. It can only be met (by believing truly), respected (by believing rationally), etc. The other key idea is this implication of Fitting Response Derivation: having an epistemically fitting response to epistemic value is derivatively epistemically valuable. If we join these ideas, we can understand non-teleological epistemic value derivation. For we can compile a list of fitting non-teleological responses to the epistemic value of truth in belief. Given Fitting Response Derivation, these help us construct the non-teleological value derivation relations we need.

What might the non-teleological responses be? To answer this question, we can focus on cases. Consider norms of structural rationality, like:

Suspend. Suspend belief in P if you think you lack sufficient evidence for P and for $\sim \mathrm{P}$. 
Violating Suspend is pro tanto epistemically bad. It is plausible that the explanation of this has something to do with truth.

But what? In general: nothing instrumental. One can violate Suspend while believing only truths at the first order and many. And one's beliefs about the evidence may badly mislead, so that complying deprives one of many true first-order beliefs.

This should not lead us to think that the explanation is not truth-oriented. Consider someone who is disposed to violate Suspend. It is natural to think this person cannot be fully committed to treating truth as authoritative in belief-formation. This plus the claim that violating Suspend is epistemically bad is evidence that the epistemic value of truth in belief is not merely teleological. It points to a response besides "promotion" called for by the epistemic value of truth in belief-viz., commitment.

Truth is not epistemically good just because we should promote true belief, by believing only truths and many. It is also an epistemic value because we should be committed to the standard of truth in belief. Otherwise there is no clear reason why violating Suspend is always epistemically bad.

Now, mere commitment is not enough. It only requires complying with norms of structural coherence. One could comply with these while ignoring non-doxastic appearances. This is epistemic negligence.

How can a T-Monist explain why that is epistemically bad? Instrumental explanations fail. Our subject might find herself in a demon world, in which following the appearances would not promote true belief. But the same strategy can be used as before. We should find a response called for by the epistemic value of the standard of truth in belief such that having it obviates epistemic negligence. Then, we apply Fitting Response Derivation.

Here respect for the standard of truth in belief helps. For an epistemically negligent subject plausibly lacks such respect.

But what does such respect involve? There are different views. I think it involves complying with all requirements of substantive epistemic rationality. This requires responding to apparent epistemic reasons. Of course, appearances may mislead. One can't be faulted with irrationality if so. (I don't conflate this with the claim that one is justified. Rationality may not yield justification.)

One might take a more externalist line. Consider Sosa (2001) on "love of truth":

What then does constitute our advocacy of the ideal of truth? When is our belief formation virtuously guided by that ideal? [ . . . S Sooner or later we shall need to recognize that our virtuous epistemic conduct must derive at some deep level from our virtuous nature, a nature not itself due entirely to one's free and autonomous choice... . If the conduct is really admirable ... then the constitution manifest in the evaluated conduct must itself be admirable because it helps the subject get into proper relation to the truth. $(56-7)$

Sosa need not be read as denying that we ought epistemically to respect the standard of truth in belief. He need only be advocating an externalist model of what it takes for intellectual conduct to be truth-respecting in the foundational case. 
He thinks it can't consist in explicitly following truth-promoting rules, via some practical syllogism. It rather consists in having and manifesting certain basic cognitive abilities.

Differences between these views need not concern us here. Both parties can agree that the standard of truth in belief takes respect as an epistemically fitting response. Both can then explain the epistemic value of rationality via the fact that proceeding rationally constitutes respecting the standard of truth in belief. It is epistemically good because such respect is, and such respect is because it is a fitting response to the standard. This fits with T-Monism. All epistemic value is grounded in that of the standard of truth in belief-just non-teleologically.

$$
* * *
$$

T-Monists can, then, explain much if they go pluralist in other ways-about kinds of fitting responses to epistemic value and kinds of value derivation. They can hereby explain the extra epistemic value of rationality, and thereby vindicate the Minimal Knowledge Intuition. After all, knowing requires rationally believing, and the kind of value derivation at issue undermines the Generalized Swamping Premise.

Since it is so seductive to think truth is fundamental to epistemic value, I'd say that what the swamping problem really teaches is that we ought to reject $\mathrm{T}_{\mathrm{NFV}}$.

Notably, everyone should ditch $\mathrm{T}_{\mathrm{NFV}}$, even if they pan T-Monism for other reasons. For focus just on fitting pro-responses to the standard of truth, like respect. No one should deny that such responses are epistemically valuable. But they are not fundamentally epistemically valuable. Adding to the stock of fundamental epistemic values here seems silly. Yet we can't avoid it unless we reject $\mathrm{T}_{\mathrm{NFV}}$. For respecting the standard of truth needn't instrumentally conduce to further instantiations of fundamental epistemic value. So unless we accept a gratuitous pluralism, we must deny $\mathrm{T}_{\mathrm{NFV}}$.

\section{The problem's limited scope}

We now see that it is wrong to regard T-Monism as the source of the swamping problem. If T-Monists in general don't face it, who does?

Anyone who can apply the model of Fitting Response Derivation to knowledge or to knowledge-entailed statuses like rationality can avoid the problem. Many T-Monists, internalist and externalist alike, can apply this model.

But as far as I can see, simple reliabilists cannot. They would have to claim that forming beliefs via reliable processes is always a fitting response to the epistemic value of the standard of truth in belief. This is implausible. Consider Greco's (1999) "strange and fleeting" cases of reliable belief-formation-cases where agents land on reliable belief-forming processes in a reflectively lucky way, or have them deviantly integrated into their psychology (say, by a brain lesion) without knowing. While these agents form beliefs reliably, they do not fittingly respond to the standard of truth in belief.

Matters seem different for virtue reliabilism, on which knowledge requires a competence ingrained in the agent's character. My proposal brings out a new reason 
why. Truly exercising such epistemic competence plausibly just is a way of respecting truth. Of course, an exercise of epistemic competence needn't be conscious or deliberate or involve explicit care or love of truth. But as Greco in effect saw (1999: 289), this shows only that these things aren't required for respecting the truth, not that proper belief-formation needn't be truth-respecting. If so, the virtue reliabilist can apply my model to explain why knowledge is epistemically better than true belief. ${ }^{6}$

Virtue reliabilism is hardly the only view that can. I suspect that the idea that truth's epistemic value calls most fundamentally for respect as a standard is the best foundation for internalist views that collapse the distinction between justification and rationality. At any rate, internalists should find this picture friendlier than objective teleological pictures on which true belief is "to be promoted". If epistemic rationality is necessary for knowledge, they too can appeal to non-teleological value derivation to explain how knowledge can be better than true belief.

So, pace Pritchard, the swamping problem is after all a limited problem. Though few T-Monists confront it, simple reliabilists may.

\section{Acknowledgments}

The substance of this paper benefited from comments by Abrol Fairweather, Clayton Littlejohn, Katy Meadows, Ernest Sosa, and an anonymous reviewer. The style benefited from comments by Kate Emma West.

\section{Notes}

1 While Kvanvig (2003) coined the 'swamping problem' label, Jones (1997) and Zagzebski (1996., 1999) were the first to discuss the problem. For other early discussions, see Riggs (2002), Zagzebski (2003b), and Sosa (2003).

2 It is Zagzebski's. See Zagzebski (1999, 2003b).

3 This differs from a thesis exploited in the literature. Brady (2006) used the buck-passers' thesis that being valuable is being the fitting object of some pro-attitude to try to aid simple reliabilism (not my aim). Fitting Response Derivation is partly stronger: the buck-passers' thesis does not imply that having a fitting pro-attitude A to X can itself be good because $\mathrm{X}$ is good and A fits X. And it is partly weaker, because Fitting Response Derivation does not entail that being valuable consists in making pro-attitudes fitting.

4 This is not to deny that having a fitting response to value is intrinsically good. There are strong reasons to distinguish between basic and non-basic intrinsic goods; see Feldman (2000) and Zimmerman (2001). This is also not to deny that fitting responses to value are organic unities. While the value of an organic unity doesn't summatively derive from the values of its parts, it hardly follows that it doesn't derive at all. Fitting Response Derivation is a non-summative kind of value derivation. This is reflected in plausible accounts of organic unities; cf. Hurka (2001)'s "recursive" account.

5 For a similar view about the responses called for by reasons, see Littlejohn (2011, 2012: Ch. 7).

6 Zagzebski (2003a: 147) uses a similar model to explain why virtue epistemology solves the value problem. 


\section{References}

Anderson, E. Value in Ethics and Economics. Cambridge, MA: Harvard University Press, 1995.

Brady, MS. "Appropriate Attitudes and the Value Problem." American Philosophical Quarterly 107 (2006):23-44.

Feldman, F. "Basic Intrinsic Value." Philosophical Studies 99 (2000):319-46.

Greco, J. “Agent Reliabilism.” Philosophical Perspectives 13 (1999):276-96.

Hurka, T. Virtue, Vice and Value. Oxford: Oxford University Press, 2001.

Jones, W. “Why Do We Value Knowledge?” American Philosophical Quarterly 34 (1997):423-39.

Kvanvig, J. The Value of Knowledge and the Pursuit of Understanding. Cambridge: Cambridge University Press, 2003.

Littlejohn, C. "Reasons and Belief's Justification." Reasons for Belief, eds. A. Reisner and A. Steglich-Petersen. Cambridge: Cambridge University Press, 2011.

Justification and the Truth-Connection. Cambridge: Cambridge University Press, 2012.

Parfit, D. On What Matters. Oxford: Oxford University Press, 2011.

Pritchard, D., A. Millar, and A. Haddock. The Nature and Value of Knowledge: Three Investigations. Oxford: Oxford University Press, 2010.

Pritchard, D. "What Is the Swamping Problem?" in Reasons for Belief, eds. A. Reisner and A. Steglich-Petersen. Cambridge: Cambridge University Press, 2011.

Riggs, W. "Reliability and the Value of Knowledge." Philosophy and Phenomenological Research 64 (2002):79-96.

Scanlon, TM. What We Owe to Each Other. Cambridge, MA: Harvard University Press, 1998.

Sosa, E. "For the Love of Truth?" in Virtue Epistemology, eds. A. Fairweather and L. Zagzebski.

Oxford: Oxford University Press, 2001.

—. "The Place of Truth in Epistemology." in Intellectual Virtue, eds. M. DePaul and

L. Zagzebksi. Oxford: Oxford University Press, 2003.

Zagzebski, L. Virtues of the Mind. Cambridge: Cambridge University Press, 1996.

_. "From Reliabilism to Virtue Epistemology." Proceedings of the Twentieth World Congress of Philosophy (Boston, 1998) v.: Epistemology, eds. R. Coff-Steven. Bowling Green, OH: Philosophy Documentation Center, 1999.

- "Intellectual Motivation and the Good of Truth." Intellectual Virtue, eds. M. DePaul and

L. Zagzebksi. Oxford: Oxford University Press, 2003a.

. "The Search for the Source of the Epistemic Good." Metaphilosophy 34 (2003b):12-28.

Zimmerman, M. The Nature of Intrinsic Value. Lanham: Rowman \& Littlefield, 2001. 